\title{
Consumption and happiness: an introduction
}

\author{
Luca Stanca $^{1} \cdot$ Ruut Veenhoven ${ }^{2,3}$
}

Published online: 10 June 2015

(C) Springer-Verlag Berlin Heidelberg 2015

\section{Introduction}

The subject of happiness has long been a playground for philosophers. Since the 1970s, it has become the object of empirical research in the social sciences. In the wake of the social indicators movement, happiness became a common topic in large-scale welfare surveys, and a key topic in psychological research on mental health and in medical research on 'health-related quality of life.' Around 2000, 'Happiness Economics' appeared on the scene (e.g., Frey and Stutzer 2002; VanPraag and Ferrer-i-Carbonell 2010).

The starting point of the literature on economics and happiness is an empirical finding, generally referred to as the Easterlin paradox: while across individuals and countries higher income results in higher happiness, over time income growth is not associated with higher happiness levels (Easterlin 1974). ${ }^{1}$ Motivated by this

\footnotetext{
1 The empirical content of the Easterlin paradox has been recently challenged on the basis of newly available time series data, showing that average happiness has risen in most nations and more so in the nations that had faster economic growth (Veenhoven and Vergunst 2014). Yet, the effect of economic growth on happiness is small.

Ruut Veenhoven

Veenhoven@ese.eur.nl

Luca Stanca

luca.stanca@unimib.it

1 Department of Economics and Neuro-Mi, University of Milan Bicocca, Piazza Ateneo Nuovo 1, U6/3062, Milan, Italy

2 Erasmus Happiness Economics Research Organization (EHERO), Erasmus University Rotterdam, POB 1738, 3000 DR Rotterdam, The Netherlands

3 Opentia Research Programme, North-West University, Vanderbijlpark, South Africa
} 
puzzling result, a large number of studies in the economics and happiness literature have investigated the relationship between income and happiness (Clark et al. 2008; Stevenson and Wolfers 2008; Stanca 2010). Three main types of explanations have been offered for the Easterlin paradox, based on hedonic, aspirational, or positional mechanisms (Easterlin et al. 2010). More recently, the relational treadmill has been proposed as an additional explanation, based on the interplay between economic conditions and interpersonal relations (e.g., Gui and Stanca 2010; Stanca 2009, 2012; Colombo and Stanca 2014). The common theme in all these explanations is that although our material conditions improve, some other change occurs at the same time with an opposite effect. As a consequence, similar to the position of a runner during a treadmill workout, our perceived well-being remains unchanged.

Forty years since Easterlin's seminal contribution, a large body of evidence is available about the relationship between income and happiness. Quite surprisingly, instead, relatively little is known about the effects of the level and composition of consumption on happiness. This special issue aims at filling this gap. It draws on papers presented at a workshop on 'Consumption and Happiness,' organized by Ruut Veenhoven within the conference 'Advances in Happiness Economics,' held at Erasmus University Rotterdam in the Netherlands, on October 28-29, 2013. This paper provides a short introduction to the special issue. We start by discussing different concepts and measures of happiness in Sects. 2 and 3, respectively. We then briefly review, in Sect. 4, the existing literature on consumption and happiness. Finally, Sect. 5 introduces the papers contained in the special issue by outlining their respective contributions.

\section{Concepts of happiness}

Since the term happiness is used with very different meanings in different disciplines, we start by spelling out alternative definitions, in order to clarify what concept of happiness is addressed in this issue. In philosophy, the word 'happiness' was used as an umbrella term for 'the good life,' and different qualities of life were called by this same name. Quality-of-life concepts can be grouped by using two distinctions, one between life chances and outcomes, and another between outer and inner qualities of life. In combination, these two dichotomies yield a four-group taxonomy of qualities of life (Veenhoven 2000): livability of the environment, lifeability of the person, usefulness of life, and satisfaction with life.

Livability of the environment denotes the meaning of good living conditions, in short, 'livability.' Economists associate livability with access to goods and services and call it 'welfare.' Livability is not what is called 'happiness' here. It is rather a precondition for happiness, and not all environmental conditions are equally conducive to happiness (e.g., Colombo et al. 2014).

Life-ability of the person denotes inner life chances. That is, how well we are equipped to cope with the problems of life. Sen (1992) calls this quality-of-life variant 'capability.' The simple term 'life-ability' is to be preferred, as it contrasts elegantly with 'livability.' An ability to deal with the problems of life will mostly contribute to happiness as defined here, but it is not identical to happiness. If one is 
competent at living, one then has a good chance at experiencing happiness, but being thus endowed does not guarantee an enjoyable life outcome.

Usefulness of life represents the notion that a good life must be good for something more than itself. This assumes that a life has some higher value. There is no current generic term for these external outcomes of life. Gerson (1976) refers to these effects as 'transcendental' conceptions of quality of life. Economists would call it 'externalities.' Leading an objectively useful life may contribute to one's subjective appreciation of life, but it may also come at the cost of that. Therefore, useful living is not the same as a happy living.

Satisfaction with life represents the inner outcomes of life. That is, the quality of a life in the eye of the beholder. As we deal with conscious humans, this quality boils down to subjective satisfaction with life. This is commonly referred to by terms such as 'subjective well-being,' 'life satisfaction,' and 'happiness' in a limited sense of the word. This is the kind of happiness addressed in this issue.

Even when we focus on subjective satisfaction with life, there are still different meanings associated with the word happiness. These meanings can be categorized on the basis of the distinction between parts-of-life versus life-as-a-whole, and the one between passing versus enduring satisfaction. These two dimensions produce a four-group taxonomy for satisfaction (Veenhoven 2000): pleasure, domains satisfaction, peak-experience, and life satisfaction.

Pleasure represents passing enjoyments of life-aspects. Examples would be delight in a cup of tea at breakfast, the satisfaction of a chore done, or the enjoyment of a piece of art. This category can be referred to as 'pleasures.' Kahneman (1999) calls it 'instant-utilities.' Although fleeting enjoyment obviously contributes to a positive appreciation of life, it is not the whole of it.

Satisfaction with life domains denotes enduring appreciation of life-aspects, such as marriage satisfaction and job satisfaction. Domain satisfactions are often denoted with the term happiness: 'a happy marriage,' 'happy with one's job,' etc. Yet, one would not call happy a person who is satisfied with her marriage and job but still dissatisfied on the whole because her health is failing.

Peak-experience denotes the combination of passing experience and appraisal of life-as-a-whole. This combination occurs typically in peak-experiences, which involve short-lived but quite intense feelings and the perception of wholeness. This is the kind of happiness poets write about, but not the kind of happiness addressed in this issue. A moment of bliss is not the same as enduring appreciation of life.

Life satisfaction represents lasting satisfaction with one's life-as-a-whole. This is the meaning addressed in this issue and is central in happiness economics. Happiness and consumption are often equated in classic economics and referred to as 'utility.' Yet, a consumption good such as a house is an external condition for happiness that, in the first taxonomy above, belongs to the livability of the environment, while happiness itself belongs to subjective enjoyment of life. Next, not all satisfaction is life satisfaction. A consumer may be very satisfied in the domain of housing, but not satisfied with his life-as-a-whole, because he had to work all the time to pay for the big house. Likewise, passing pleasures derived from consumption should not be equated with its long-term consequences for life satisfaction. One may enjoy more than five glasses of alcohol a day, while this 
consumption pattern still reduces life satisfaction in the long run. The question at stake in this issue is what patterns of consumption add more or less to enduring life satisfaction.

\section{Measures of happiness}

Since happiness is defined as something that we have in mind, it can be measured using questions. Questions on happiness can be presented in various ways (Veenhoven 2012a). A common direct question is 'Taking all things together, how happy would you say you are?' Indirect questions ask related things, such as 'Do you think that you are happier than most people in this country' or 'Do you often sing when under the shower?' An assumed advantage of indirect questioning is that this will reduce response bias. A disadvantage is that something different than happiness is measured.

Rather than using single questions as in the example above, one can ask about the same using multiple questions. Series of questions on happiness are referred to as 'scales,' and the Satisfaction With Life Scale (SWLS) is one of the most common questionnaires (Diener et al. 1985). An advantage of single questions is that is clear what is being measured and hence that one can easily see whether that is happiness as subjective enjoyment of one's life-as-a-whole (face validity). A disadvantage is that the particular words used may not be interpreted in the same way by all respondents. An advantage of multiple questions is that such differences in interpretation balance out. Yet, a disadvantage is that the questions may not quite address the same thing, such as the last item in Diener's SWLS.

The above-mentioned single question calls for a global estimate by the respondent, which may involve various biases (Kahneman 1999). An alternative is to ask repeatedly how happy one feels at the moment and to compute an average. This is referred to as the Experience Sampling Method (ESM), a variant of which is the Day Recall Method (DRM). These method can be used to measure only the affective component of happiness, referred to above as 'hedonic level of affect.'

The hedonic level of affect can also be measured indirectly by asking people about particular feelings in the recent past, such as how often they felt 'cheerful' or 'blue.' The reported number of negative affects is then subtracted from the number of positive experiences. A common scale of that kind is Bradburn's (1969) 10-item 'Affect Balance Scale.' This technique fits well with Bentham's (1789) classic notion of happiness as 'the sum of pleasures and pains.'

An overview of happiness questions is available in the collection 'Measures of Happiness' of the World Database of Happiness, which includes about 900 variants (Veenhoven 2015a, b). There is a large literature on the quality of these measures, their validity, reliability, and comparability across persons and cultures. Comprehensive reviews are presented in Larsen et al. (1985) and Veenhoven (2012b). 


\section{Happiness and consumption}

Research in happiness economics has focused mainly on the effects of income and employment, that is, on how much and in what way money is earned. ${ }^{2}$ As yet, there has been relatively little interest in the effects on happiness of how earnings are spent. ${ }^{3}$ In addition, the available findings are all cross-sectional and generally do not inform us about cause and effect (MacDonald and Douthitt 1992; Headey et al. 2004; DeLeire and Kalil 2010; Perez-Truglia 2013; Lewis 2014).

In modern multiple-choice society we face several major consumer choices, such as when we buy a house, a car, or a life insurance. Expectations about happiness play a key role in such decisions. People who spend a large part of their income on a spacious house typically expect that life will be more satisfying in a big house and might take up a heavy mortgage in order to prevent the unhappiness expected from living in a smaller house.

Yet, predictions of future happiness appear to be subject to many distortions (e.g., Gilbert 2006). In this context, Kahneman and Thaler (2006) distinguished between expected utility and experienced utility, the latter being the ultimate effect on happiness. Likewise, Frey and Stutzer (2014) coined the expression mis-predicting utility, which results in a loss of happiness. Their iconic example is the person who accepts a better paying job at a longer distance, expecting that the better pay will add to his happiness, whereas the longer commuting time actually makes him less happy overall (Stutzer and Frey 2008).

There are several ways to deal with the problem of misinformed consumer choice. One way is to combat misleading information by means of rules for advertising and counter-information by consumer unions. A related approach is consumer education. Still another way to more informed choice is to gather information about the long-term effects of consumer choice, for instance by following over time the happiness of otherwise comparable people who bought a big or a small house. Such information can be used both for correcting misleading claims in advertisements and for consumer education. This approach is comparable to effect research on pharmaceutics, which is also used to check claims by producers and to inform health education.

The long-term effects of consumer choice on happiness are likely to differ across persons. So the question is not only whether most people are happier in a bigger house, but also among what kind of people happiness depends on the size of the house.

The first key research question is 'How much consumption is optimal for happiness?' Are frugal people really happier than big spenders, as some studies on happiness and materialism suggest (e.g., Hudders and Pandelaere 2012)? A second question is 'What types of consumption are most conducive to happiness?' Is experience consumption more satisfying than material consumption? In the case of

\footnotetext{
${ }^{2}$ World Database of Happiness, Findings on Happiness and Income and Happiness and Employment (Veenhoven 2015a).

3 Of the 14,000 correlational findings in happiness, only about 100 concern the relationship between consumption and happiness (World Database of Happiness, Findings on Happiness and Consumption, Veenhoven 2015a).
} 
experience consumption, a more specific question is 'What kind of experiences add most to happiness?' And, when it comes to material consumption, what durable goods add most to happiness? Does investment in housing pay off more than in cars? In all these issues we are faced with further questions about variations across persons and situations. This leads to a more general fundamental question: to what extent and on what issues can empirical research contribute to more informed choice?

Given the relevance of these questions, and the size of the market, one would have expected much more research on the consequences of consumer choice on happiness. Why is there only a handful of findings about consumption and happiness, for example, in the World Database of Happiness (2015a)?

One of the reasons seems to be the theoretical limitations of mainstream economics. Many researchers still equate consumption and happiness, implicitly assuming that homo economicus is fully informed about his preferences and that meeting these preferences will make him happy. They are often unaware of the above-noted difference between expected and experienced utility. They underestimate the importance of the difference between needs and wants and tend to overlook the fact that happiness depends more on meeting the former than the latter (Veenhoven 2009).

Another reason is commercial interest. Producers are interested in selling their products in the first place. They spend large amounts of money on marketing research to obtain a better picture of what consumers expect that will make them happy, and on advertisement to influence these expectations and link to their products. Whether these products actually add to consumers' happiness is not necessarily of interest. Although there is a substantial body of research on consumer's satisfaction with the product, there is little research on the effects on life satisfaction, not even in the domains of housing and residential care.

This lack of research is part of a wider market failure. Since there is no reliable information about the long-term consequences for happiness of large consumer purchases, there is no competition on happiness effects and hence no product development in that direction. The market itself is unlikely to solve this problem. Governments and consumer unions would be, instead, in the position to press for more research on the effects of consumption on happiness.

\section{Contributions in this issue}

This special issue contains five empirical papers providing new evidence on the relationship between the level and composition of consumption and subjective wellbeing. Overall, the papers provide a wide range of contributions, from different perspectives, to the understanding of the relationship between consumption and happiness.

In the first paper, Noll and Weick (2015) investigate the effects of the level and composition of consumption on life satisfaction among German households. They use cross-sectional data from the German Socio-Economic Panel (SOEP), which includes, since 2010, retrospective information on households' 
consumption expenditures. Total consumption expenditures are found to exert a positive and significant effect on life satisfaction. The size of the effect is substantial and only marginally lower than that of household income. Turning to the composition of consumption, expenditures on clothing and leisure are identified as key determinants of subjective well-being, while expenditures on food and housing are not significantly related to life satisfaction. The explanatory power of the model rises substantially when replacing total expenditures with the amount spent on different categories of goods and services. Finally, the analysis indicates that there are differences in the effects of income and consumption across different parts of the respective distributions. Individuals in the lowest consumption decile are less unsatisfied with their life than individuals in the lowest income decile. In addition, low levels of consumption expenditures are found to reduce life satisfaction only marginally when people voluntarily choose to consume less.

Okulicz-Kozaryn (2015) investigates the effects of car consumption on life satisfaction. Using the 2011 wave of the American Panel Study of Income Dynamics (PSID), the paper focuses on the role played by car ownership, number of cars owned, and type of car (luxury versus frugal). The findings indicate that, controlling for income and house ownership, car ownership does not have a significant effect on life satisfaction. The relationship between number of cars owned and well-being is shown to be sensitive to the set of control variables. Most importantly, luxury cars are not found to contribute to happiness more than frugal cars. An interesting interpretation of these results is that conspicuous, or positional, consumption may help to explain the Easterlin paradox.

Zhang and Xiong (2015) study the effects of consumption choices on several indicators of happiness, focusing on a large set of consumption categories from different life domains and including both monetary and experiential consumption. The analysis relies on a web-based survey conducted in 2010 on 2,178 individuals in various cities of Japan. The results indicate that while more than half of the 77 consumption variables from eight life domains affect happiness, different happiness domains are influenced by different sets of consumption variables. In particular, while income only affects overall happiness and experiences of mildly pleasant moods during leisure activities, saving is the most important factor for enhancing overall happiness. Happiness is strongly affected by active life consumption variables and communication with neighbors.

The last two papers in this special issue rely on the Life in Transition Survey conducted jointly by the European Bank for Reconstruction and Development (EBRD) and the World Bank in 2010, which includes detailed information on several consumption categories, such as expenditures on food, education, and durables. Dumludag (2015) studies the effects of various consumption expenditures on life satisfaction at different levels of development. Interestingly, the findings indicate that the relationship between consumption categories and life satisfaction differs depending on levels of development. While expenditures on clothing and footwear and durables have a positive and significant effect on well-being in both developed and transition economies, expenditure on utilities has a positive effect on well-being in transition countries but no effect in developed countries. Gokdemir 
(2015) carries out a similar analysis with a focus on Turkey. The findings indicate that, overall, only expenditures for durable goods and savings are positively and significantly related to life satisfaction.

\section{References}

Bentham J (1789) An Introduction to the principles of morals and legislation. London

Bradburn N (1969) The structure of psychological well-being. Aldine Publishing, Chicago

Clark A, Frijters P, Shields M (2008) Relative income, happiness and utility: an explanation for the Easterlin paradox and other puzzles. J Econ Lit 46(1):95-144

Colombo E, Stanca L (2014) Measuring the monetary value of social relations: a hedonic approach. J Behav Exp Econ 50:77-87

Colombo E, Michelangeli A, Stanca L (2014) La Dolce Vita: hedonic estimates of quality of life in Italian cities. Reg Stud 48(8):1404-1418

DeLeire T, Kalil A (2010) Does consumption buy happiness? Evidence from the United States. Int Rev Econ 57(2):163-176

Diener E, Emmons RA, Larsen RJ, Griffin S (1985) The satisfaction with life scale. J Personal Assess 49:71-75

Dumludag D (2015) Consumption and life satisfaction at different levels of economic development. Int Rev Econ 62(2). doi:10.1007/s12232-015-0226-z

Easterlin R (1974) Does economic growth improve the human lot? In: David PA, Reder MW (eds) Nations and households in economic growth: essays in honor of Moses Abramovitz. Academic Press, New York

Easterlin R, Angelescu L, Switek M, Sawangfa O, Smith J (2010) The income-happiness paradox revisited. Proc Natl Acad Sci 107(52):22463-22468

Frey B, Stutzer A (2002) Happiness and economics. Princeton University Press, Princeton

Frey B, Stutzer A (2014) Economic consequences of mispredicting utility. J Happiness Stud 15:937-956

Gerson EM (1976) On quality of life. Am Sociol Rev 41:793-806

Gilbert D (2006) Stumbling on happiness. Knopf, New York

Gokdemir O (2015) Consumption, savings and life satisfaction: the Turkish case. Int Rev Econ 62(2). doi:10.1007/s12232-015-0227-y

Gui B, Stanca L (2010) Happiness and relational goods: well-being and interpersonal relations in the economic sphere. Int Rev Econ 57(2):105-118

Headey B, Muffels R, Wooden M (2004) Money doesn't buy happiness... or does it? A reconsideration based on the combined effects of wealth, income and consumption. IZA Discussion Paper No. 1218. Bonn

Hudders L, Pandelaere M (2012) The silver lining of materialism: the impact of luxury consumption on subjective well-being. J Happiness Stud 13:411-437

Kahneman D (1999) Objective happiness. In: Kahneman D, Diener E, Schwarz N (eds) Well-being: the foundations of hedonic psychology. Russell Sage Foundation, New York, USA, pp 3-25

Kahneman D, Thaler RH (2006) Anomalies, utility maximization and experienced utility. J Econ Perspect 20:221-234

Larsen RJ, Diener E, Emmons RA (1985) An evaluation of subjective well-being measures. Social Indic Res 7:1-17

Lewis J (2014) Income, expenditure and personal well-being, research report, UK Office for National Statistics. Newport, South Wales (www.ons.gov.uk/ons/dcp171766_365207.pdf. Accessed 6 Oct 2014)

MacDonald M, Douthitt RA (1992) Consumption theories and consumer's assessments of subjective well-being. J Consum Aff 26(2):243-261

Noll H and Weick S (2015) Consumption expenditures and subjective well-being: empirical evidence from Germany. Int Rev Econ 62(2). doi:10.1007/s12232-014-0219-3

Okulicz-Kozaryn A (2015) Luxury car owners are not happier than frugal car owners. Int Rev Econ 62(2). doi:10.1007/s12232-015-0223-2 
Perez-Truglia R (2013) A test of the conspicuous-consumption model using subjective wellbeing data. J Socio Econ 45:146-154

Sen A (1992) Capability and wellbeing. In: Sen A, Nussbaum M (eds) The quality of life. Clarendon Press, Oxford, pp 30-53

Stanca L (2009) With or without you: measuring the quality of relational life throughout the world. J Socio Econ 38:834-842

Stanca L (2010) The geography of economics and happiness: spatial patterns in the effects of economic conditions on well-being. Social Indic Res 99(1):115-133

Stanca L (2012) Suffer the little children: measuring the effects of parenthood on well-being worldwide. J Econ Behav Organ 81(3):742-750

Stevenson B, Wolfers J (2008) Economic growth and subjective well-being: reassessing the Easterlin paradox. In: Brookings papers on economic activity, Economic Studies Program, The Brookings Institution, vol 39(1), pp 1-102. NBER Working Paper No. 14282

Stutzer A, Frey B (2008) Stress that doesn't pay: the commuting paradox. Scand J Econ 110:339-366

VanPraag B, Ferrer-i-Carbonell A (2010) Happiness economics: a new road to measuring and comparing happiness. Found Trends Microecon 6:1-97

Veenhoven R (2000) The four qualities of life. Ordering concepts and measures of the good life. J Happiness Stud 1:1-39

Veenhoven R (2009) How do we assess how happy we are? In: Dutt A, Radcliff B (eds) Happiness, economics and politics: towards a multi-disciplinary approach. Edward Elger Publishers, Cheltenham UK, pp 45-69

Veenhoven R (2012a) Evidence based pursuit of happiness: What should we know, do we know and can we get to know?. Erasmus Happiness Economics Research Organization, White Paper nr 1

Veenhoven R (2012b) Cross-national differences in happiness: cultural measurement bias or effect of culture? Int J Wellbeing 2:333-353

Veenhoven R (2015a) World database of happiness. Erasmus University Rotterdam, Netherlands. http:// worlddatabaseofhappiness.eur.nl

Veenhoven R (2015b) Measures of happiness. World database of happiness. Erasmus University Rotterdam. http://worlddatabaseofhappiness.eur.nl/hap_quer/hqi_fp.htm

Veenhoven R, Vergunst F (2014) The Easterlin illusion: economic growth does go with greater happiness. Int J Happiness Dev 1(4):311-343

Zhang J, Xiong Y (2015) Effects of multifaceted consumption on happiness in life: a case study in Japan based on an integrated approach. Int Rev Econ 62(2). doi:10.1007/s12232-015-0225-0 